Saudi Journal of Medicine

Abbreviated Key Title: Saudi J Med ISSN 2518-3389 (Print) |ISSN 2518-3397 (Online)

\title{
A Study of Pathological Complications of Upper Respiratory Tract Infections
}

\author{
Dr. Krishna Prasad R ${ }^{1}$, Dr. Shreesha Khandige ${ }^{2^{*}}$ \\ ${ }^{1}$ Associate Professor, Department of TB and Chest (Respiratory Medicine), Kanachur Institute of Medical Sciences, Deralakatte, Mangalore. \\ ${ }^{2}$ Professor and HOD, Department of Pathology, Kanachur Institute of Medical Sciences, Deralakatte, Mangalore India
}

DOI: $10.36348 /$ sjm.2020.v05i02.006 | Received: 02.02.2020 | Accepted: 09.02.2020 | Published: 14.02 .2020

*Corresponding author: Dr. Shreesha Khandige

\section{Abstract}

Respiratory infections are quiet common in today's world. Endemics ad Pandemics like SARS and Corona Virus infections has made headlines already. Especially in the urban or semi developed areas the people more prone to such conditions. This study puts in an effort to find pathological complications of Upper respiratory tract.

Keywords: Upper, Respiratory tract, Infections, Under 5 years.

Copyright @ 2020: This is an open-access article distributed under the terms of the Creative Commons Attribution license which permits unrestricted use, distribution, and reproduction in any medium for non-commercial use (NonCommercial, or CC-BY-NC) provided the original author and source are credited.

\section{INTRODUCTION}

Respiratory infections are quiet common in today's world. Endemics ad Pandemics like SARS and Corona Virus infections has made headlines already. Especially in the urban or semi developed areas the people more prone to such conditions. This study puts in an effort to find pathological complications of Upper respiratory tract $[1,2]$. Among under-fives, ARI cause specific mortality in $20-25 \%$. On this basis, one million deaths among under-fives in our Country are due to ARI and most of these occur in infants [3]. Cause specific mortality due to ARI is 10 to 50 times higher in developing countries than developed countries [4]. In our country, $14.3 \%$ of deaths during infancy and $15.9 \%$ of deaths between 1-5 years of age are due to ARI [5]. In India, pneumonias are estimated to be responsible for $75 \%$ of ARI deaths [6] which can be secondary to the upper tract infections. Most common organisms known to cause ARI among children include bacteria such as Staphylococcus aureus, Streptococcus pyogenes, Pneumococci, Haemophilus influenzae \& Klebsiella pneumonia. Viruses such as Adeno, Rhino, and Corona \& Influenza are also the common etiological agents [7]. This study puts in an effort to find a pattern of Upper Respiratory Tract Infections in Children less than 5 years so as to be useful to the practicing doctors of the locality.

\section{AIMS AND OBJECTIVES}

To study the pathological complications of Upper Respiratory Tract Infections

\section{MATERIALS AND METHODS}

This study was done in the Department of Respiratory medicine in association with the Department of Pathology, Kanachur Institute of Medical Sciences, mangalore.

This study was done from April 2017 to May 2018 for a period of 14 months. The study was done in 400 cases that were delivered and a reference had been sought from the Department of Pediatrics.

\section{Inclusion Criteria}

Clinically proven cases

\section{Exclusion Criteria}

therapy

On steroid and other immunosuppressant

\section{RESULTS}

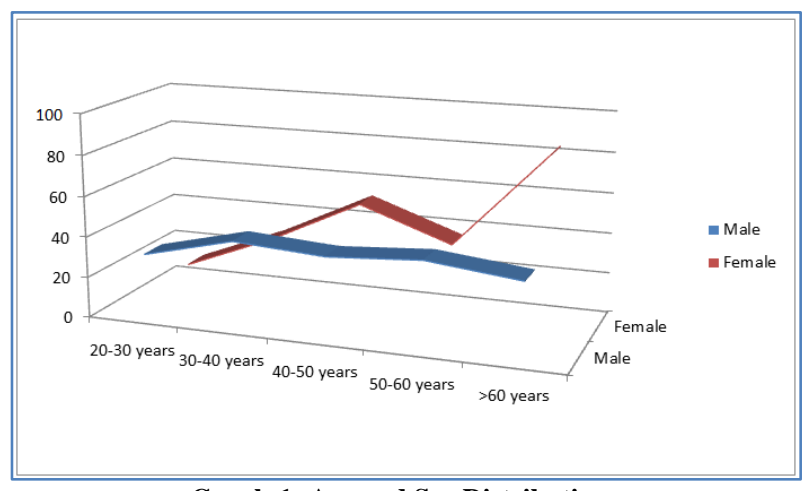

Graph-1: Age and Sex Distribution 


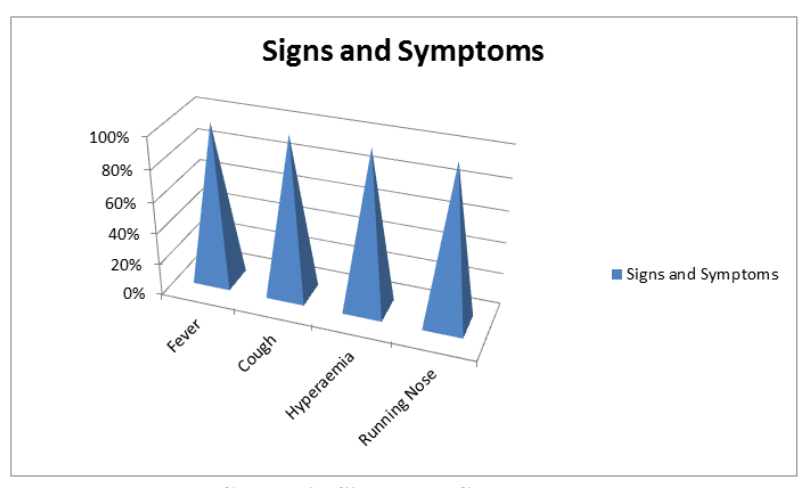

Graph-2: Signs and Symptoms

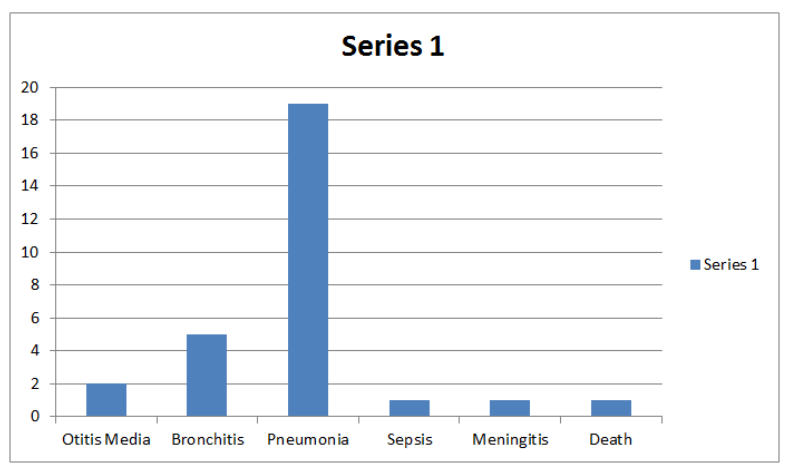

Graph-3: Complications

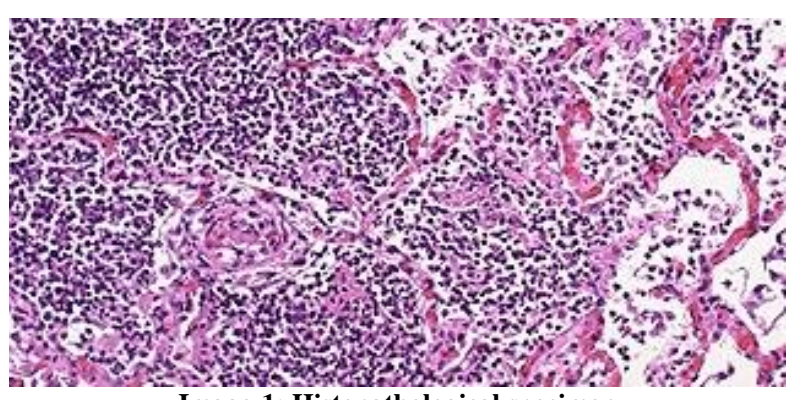

Image-1: Histopathological specimen

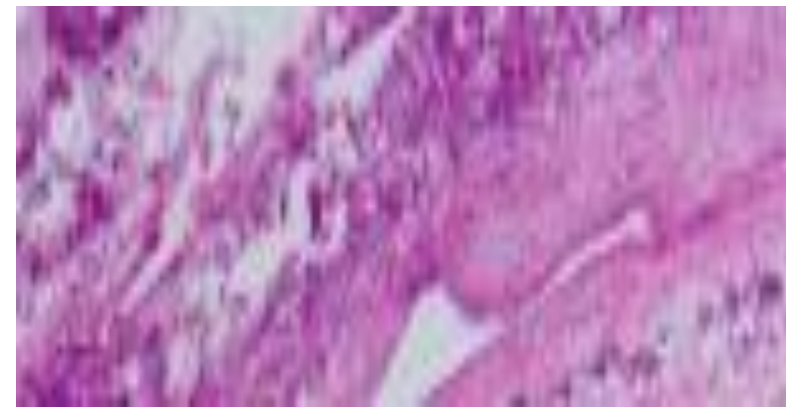

Image-2: Histopathology of Meningitis

\section{DISCUSSION}

Most respiratory tract infections, with the exception of pneumonia and the flu, do not cause complications. Some of the complications that are associated with pneumonia and flu are. Pneumonia, Pleurisy, pleuritic pain and pleural effusion. Pleurisy is when the two thin linings between your lungs and your ribcage (the bones in your chest) become inflamed. Pleurisy can be caused by lung conditions such as pneumonia. Sometimes, the symptoms of severe pneumonia can include pleuritic pain, which is a sharp, stabbing pain in your chest that occurs in one place when you breathe in. This can also be a symptom of pleurisy. Less commonly, fluid can build up in the space between your lungs and the wall of your chest. This is known as a pleural effusion. If this fluid becomes infected (empyema), it will usually be drained using a needle or a thin tube. Other complications of pneumonia can include:

- deep vein thrombosis (DVT)

- lung abscess

- blood infection, such as septicaemia or bacteraemia

Blood infections can make you very ill and normally need to be treated in hospital. Rarely, pneumococcal pneumonia can cause an infection of the membranes that cover the brain (pneumococcal meningitis). Flu commonly caused by the influenza is the most commonly encountered and the complication of flu is a secondary bacterial chest infection which develops in addition to the viral infection. Occasionally, this can become serious and develop into pneumonia. A course of antibiotics will usually be successful in curing the infection but sometimes it can become lifethreatening, particularly in those who are frail and elderly. Other serious complications of flu are uncommon. Blood supplies oxygen to the body and removes carbon dioxide. It is pumped around the body by the heart. Drowsiness is when someone feels extremely tired and uncontrollably near to sleep. A high temperature, also known as a fever, is when someone's body temperature goes above the normal 37C (98.6F). Wheezing is the whistling sound made during breathing when the airways are blocked or compressed.

\section{CONCLUSION}

Proper antibiotics should be prescribed. Treatment should be point oriented and also very prompt. This silent disease has the potential to kill is a statement of this present study.

\section{REFERENCES}

1. Nilanjan, M.K.(2001). A longitudinal study on ARI among rural under-fives. Indian Journal of Community Medicine, 26:8-11.

2. Singh, M.P., Nayar, S. (1996). Magnitude of Acute Respiratory Infections in fewer than five children. Journal of Communicable diseases, 28(4):273-78.

3. Reddaiah, V.P., Kapoor, S.K. (1988). Acute respiratory infections in rural underfives. Indian $J$ Paediatr, 55:424-26.

4. Acharya, D. (2003). Acute respiratory infections in children: A community based longitudinal study in south India. Indian Journal of Public health, 47:712.

5. Savitha, M.R. (2005). Proceedings from Karnatatka State Paediatrics conference. Gulbarga, India: 2005 Dec 29-30. Modifiable risk factors for acute lower respiratory tract infections in children. 
6. Reddaiah, V.P., Kapoor, S.K. (1990). Epidemiology of Pneumonia in rural underfives. Indian J Paediatr, 57:701-04.

7. Park, K. (2005). Textbook of Preventive and Social Medicine. 18th Ed. Jabalpur: Banarsidas bhanot publishers, 350.

8. Kapoor, S.K., Reddaiah, V.P., Murthy, G.V.S.(1990). Knowledge, Attitude and Practices regarding Acute Respiratory Infections. Indian $J$ Paediatr, 57:533-35.

9. Gupta, K.B., Walia, B.N.S. (1980). A longitudinal study of morbidity in children in a rural area of Punjab. Indian J Paediatr, 47:297-301.
10. Sharma, A.K., Reddy, D.C.S., Dwivedi, R.R.(1999). Descriptive epidemiology of acute respiratory infections among fewer than five children in an urban slum area. Indian journal of public health, 43(4):156-59.

11. BOSTID researchers. (1990). The Epidemiology of Acute Respiratory Tract Infection in Young Children: Comparison of findings from several developing Countries. Reviews of Infectious Diseases, 12(8):S870-87. 